\title{
Hepatite Colestática Aguda Secundária a Amoxicilina/Ácido Clavulânico
}

\section{Acute Cholestatic Hepatitis Caused by Amoxicilin/Clavunate}

Marisa Rosete ${ }^{1}$, Joana Antunes ${ }^{1}$, Margarida Gaudêncio르. Fernando Ferraz e Sousa ${ }^{1}$, Amélia Pereira ${ }^{1}$

\section{RESUMO}

A amoxicilina/ácido clavulânico é um antibiótico muito usado na prática clínica para diversas infeções. Está associada a uma pequena percentagem de casos de lesão hepática secundária a fármacos, sendo a hepatite e colestase complicações raras.

Os autores apresentam o caso clínico de doente, de 65 anos, género masculino, admitido no serviço de urgência por dor abdominal, colúria, acolia fecal, prurido generalizado e anorexia com 4 dias de evolução. Nos 21 dias prévios, fez curso de 7 dias de antibioterapia com amoxicilina/ácido clavulânico por amigdalite, negando uso de outros fármacos. Dos exames complementares efetuados, destaca-se hiperbilirrubinémia direta, elevação das transaminases, fosfatase alcalina e gama-GT. As serologias víricas, bacterianas e de auto-imunidade foram negativas.

Realizou biópsia hepática que mostrou inflamação hepatocelular, colestase e lesão dos ductos biliares.

Conclui-se tratar-se de hepatite colestática secundária a amoxicilina/ácido clavulânico. Foi submetido a terapêutica de suporte, com colestiramina e ácido ursodesoxicólico para controlo de prurido, não realizando nenhum tratamento específico.

PALAVRAS-CHAVE: Colestase Intra-Hepática/etiologia; Combinação Amoxicilina e Clavulanato de Potássio/efeitos adversos; Doença Hepática Induzida por Medicamentos 


\section{ABSTRACT}

A 65-year-old man was admitted to the emergency room, with a history of abdominal pain, choluria, fecal acholia, generalized pruritus and anorexia for four days. He indicated that it had been approximately 21 days since he had used amoxicillin/ calvulanate for 7 days for tonsillitis and denied using any other medications. Laboratory data showed direct hyperbilirubinemia and elevated liver enzymes. Diagnostic investigation began with serological tests for virus, bacteria and auto-immunity which were negative. A liver biopsy was performed, and the pathology showed hepatocellular inflammation, cholestasis, and bile duct damage.

Conclusion: The patient was diagnosed with cholestatic hepatitis associated with amoxicillin/clavulanate. He did not receive any specific treatment, only cholestyramine and ursodeoxycholic acid for pruritus.

KEYWORDS: Amoxicillin-Potassium Clavulanate Combination/adverse effects; Chemical and Drug Induced Liver Injury; Cholestasis, Intrahepatic/etiology

\section{INTRODUÇÃO}

A lesão hepática induzida por fármacos (DILI) pode ser classificada em intrínseca (direta) ou idiossincrática. ${ }^{1}$

A DILI intrínseca é tipicamente dose-dependente e na maioria dos casos surge num curto espaço de tempo (horas a dias) após a exposição. ${ }^{1}$ Fármacos como o paracetamol, amiodarona, colestiramina, ciclosporina, ácido valproico, heparinas e estatinas podem estar associados a este tipo de lesão. ${ }^{1}$

Por outro lado, a DILI idiossincrática não é dose-dependente, ocorrendo numa pequena percentagem de doentes e geralmente com um período de latência de dias a semanas. ${ }^{1} \mathrm{Na}$ literatura, verifica-se que este tipo de lesão, pode estar associada a fármacos como alopurinol, amiodarona, amoxicilina/ácido clavulânico, bosentan, dantroleno, diclofenac, estatinas, fenofibratos, isoniazida, cetoconazole, leflunamida, lisinopril, metildopa, nitrofurantoína, fenitoína, sulfonamidas, entre outros. ${ }^{1}$

A incidência de lesão hepática associada ao uso de amoxicilina/ácido clavulânico é superior à que ocorre com o uso de amoxicilina isoladamente. ${ }^{2}$ Em termos de tipo de lesão, verifica-se um predomínio do atingimento colestático, no entanto, podem igualmente ocorrer lesões hepatocelulares isoladamente ou mistas. ${ }^{3}$

A fisiopatologia subjacente a este tipo de lesão requer mais estudos, mas pensa-se que a resposta alérgica imuno-mediada idiossincrásica é o principal mecanismo. $^{4}$

A identificação de autoanticorpos específicos como os anti-mitocôndria tipo 6, anti-LKM2 e anti-LM4, ${ }^{4}$ assim como, os antigénios HLA classe II (DRB1*1501-DRB5*0101-DQB1*0602) ${ }^{5}$ reforça a hipótese de se tratar de uma agressão imuno-mediada.
Os autores apresentam um caso de lesão hepática induzida por amoxicilina/ácido clavulânico, sendo, a sua manifestação clínica da hepatite colestática, evento que é descrito na literatura como raro.

\section{CASO CLÍNICO}

Doente, género masculino, 65 anos, admitido no Serviço de Urgência por dor abdominal, colúria, acolia fecal, prurido generalizado e anorexia com 4 dias de evolução.

Referia ciclo de 7 dias de antibioterapia com amoxicilina/ácido clavulânico nos 21 dias prévios, por amigdalite. Sem toma de outra medicação.

Ao exame objetivo, encontrava-se apirético, normotenso, eupneico em ar ambiente, ictérico. Auscultação cardiopulmonar sem alterações. Ao exame abdominal, verificou-se distensão abdominal e dor generalizada à palpação, sem defesa.

$\mathrm{Na}$ avaliação analítica, destaca-se elevação dos marcadores de citólise e colestase hepáticos, assim como, hiperbilirrubinémia direta (Tabela 1).

O estudo serológico de hepatite $A$, hepatite $B$, hepatite C, hepatite E, citomegalovírus, Epstein-Barr, leptospirose e HIV revelou-se negativo.

A pesquise de autoimunidade (anticorpos anti-nucleares, anti-músculo liso, anti-LKM e anti-mitocôndria, ANCA) foi negativa, sendo normal o doseamento de imunoglobulinas.

Os exames imagiológicos realizados (ecografia, tomografia computorizada e ressonância magnética abdominais) não demonstraram alterações de relevo. 
TABELA 1. Estudo analítico inicial.

\begin{tabular}{ll|l|}
\hline & Resultados & $\begin{array}{l}\text { Valores de } \\
\text { Referência }\end{array}$ \\
\hline Hemograma & & \\
\hline Leucócitos & $5,83 \times 10^{3} / \mathrm{UI}$ & $4-10,5$ \\
\hline Hemoglobina & $14,9 \mathrm{~g} / \mathrm{dL}$ & $13,5-18$ \\
\hline Plaquetas & $212 \times 10^{3} / \mathrm{UL}$ & $150-450$ \\
\hline Velocidade de Sedimentação & $5 \mathrm{~mm} / \mathrm{h}$ & $<13$ \\
\hline Bioquímica & & \\
\hline TGO & $174 \mathrm{U} / \mathrm{L}$ & $0-38$ \\
\hline TGP & $328 \mathrm{U} / \mathrm{L}$ & $0-41$ \\
\hline FA & $312 \mathrm{U} / \mathrm{L}$ & $40-129$ \\
\hline GGT & $646 \mathrm{U} / \mathrm{L}$ & $8-61$ \\
\hline Bilirrubina total & $10,47 \mathrm{mg} / \mathrm{dL}$ & $<1$ \\
\hline Bilirrubina direta & $8,93 \mathrm{mg} / \mathrm{dL}$ & $0-0,3$ \\
\hline Proteína C reativa & $9,03 \mathrm{mg} / \mathrm{L}$ & $<5 \mathrm{mg} / \mathrm{L}$ \\
\hline Coagulação & & \\
\hline Tempo de protrombina & $12,4 \mathrm{seg}$ & $9,7-14,1$ \\
\hline INR & 1,1 & $0,9-1$ \\
\hline TGO & &
\end{tabular}

$\mathrm{TGO}=$ transaminase glutâmica oxalacética; $\mathrm{TGP}=$ transaminase glutâmica pirúvica; FA = fosfatase alcalina; GGT = gama glutamil transferase; INR = razão normalizada internacional.

Foi submetido a biópsia hepática, cujo resultado anatomopatológico demonstrou a presença de inflamação hepatocelular, colestase e lesão dos ductos biliares.

O estudo dos antigénios HLA classe II, identificou os alelos DRB1*1501 e DQB1*0602.

Por suspeita de hepatotoxicidade, foi calculada a pontuação em 2 scores de risco, apresentando uma pontuação de +9 (associação muito sugestiva) no score Council for International Organizations of Medical Sciences (CIOMS) e uma pontuação de +17 (associação definitiva) no score Clinical Diagnostic Scale (CDS).

Em suma, da combinação do estudo de histocompatibilidade que demonstra suscetibilidade a hepatotoxicidade por amoxicilina/ácido clavulânico, com alterações analíticas e histológicas, foi assumido o diagnóstico de hepatite colestática secundária a amoxicilina/ácido clavulânico.

Durante o internamento, o doente apresentou um agravamento progressivo do prurido e da hiperbilirrubinémia (Tabela 2). Iniciou terapêutica sintomática com colestiramina $4 \mathrm{~g} 4$ vezes ao dia, bem como, ácido ursodesoxicólico 250 mg 3 vezes ao dia.

Três meses após início da doença, o doente tornou-se assintomático, com resolução completa da icterícia e prurido, apresentando normalização da enzimologia hepática, tendo sido suspensa a terapêutica instituída.

\section{DISCUSSÃO E CONCLUSÃO}

A DILI é um verdadeiro desafio para internistas e hepatologistas, devido ao elevado número de fármacos subjacentes, variabilidade de manifestações clínicas e ausência de marcadores específicos. ${ }^{1}$

Na literatura, diversos autores apresentam um conjunto de fatores de risco para hepatoxicidade a amoxicilina/ ácido clavulânico, nomeadamente, género masculino, consumo de álcool, ciclos repetidos de antibiótico e uso concomitante de outras drogas hepatóxicas. ${ }^{3}$ Por outro lado, a duração do tratamento com este antibiótico tem sido apresentada com fator predisponente em algumas revisões. ${ }^{4}$

Hiperbilirrubinémia severa, alteração da função hepática e manifestações neurológicas constituem fatores de mau prognóstico, com a possibilidade de evolução para hepatite fulminante. ${ }^{4}$

O tratamento deste tipo de DILI consiste em terapia de suporte e controlo sintomático, nomeadamente sintomas de colestase, sendo necessário o uso de analgésicos, anti-eméticos ou mesmo colestiramina, anti-histamínicos, sertralina ou ácido ursodesoxicólico para o controlo de prurido. ${ }^{6}$

Devido ao mecanismo imunológico subjacente, incluindo reações de hipersensibilidade mediada por eosinófilos, alguns autores defendem o uso de corticoterapia sistémica em casos severos ou com potencial de agravamento, nomeadamente nos casos de hiperbilirrubinémia. ${ }^{6}$ No entanto, este tipo de terapia não mostrou para já evidência de redução de mortalidade. ${ }^{6}$

Concluindo, os autores apresentam o caso de um doente, género masculino, 65 anos, que ao fim de 3 semanas de terapêutica com amoxicilina/ácido clavulânico, desenvolve uma hepatite colestática. O doente apresentava alguns dos fatores de risco de hepatotoxicidade (género masculino, ciclo repetido de antibiótico), assim como, alelos HLA classe II de risco e uma biópsia hepática com colestase, inflamação linfocítica periportal e dano hepatocitário, aspetos sugestivos de DILI. ${ }^{3}$

No decurso da avaliação do doente foram utilizados dois scores de risco de hepatotoxicidade: score Council for International Organizations of Medical Sciences (CIOMS) ${ }^{7} \mathrm{e}$ score Clinical Diagnostic Scale (CDS). ${ }^{8}$ A utilização de ambos os scores mostrou uma provável associação entre a lesão hepática e o uso de amoxicilina/ácido clavulânico.

Este caso demonstra a importância da realização de uma história clínica cuidada, procurando-se fazer uma caracterização dos fármacos e/ou substâncias ingeridas pelo doente, uma vez que, a DILI é cada vez mais uma enti- 
TABELA 2. Evolução da enzimologia hepática, bilirrubina e INR durante o internamento.

\begin{tabular}{|c|c|c|c|c|c|c|c|c|c|c|c|}
\hline Dia internamento & D1 & D2 & D5 & D8 & D11 & D14 & D17 & D21 & D24 & D28 \\
\hline TGO (U/L & 174 & 162 & 116 & 112 & 152 & 100 & 71 & 87 & 58 & 54 & 49 \\
\hline TGP (U/L) & 328 & 282 & 199 & 181 & 267 & 261 & 189 & 213 & 198 & 148 & 88 \\
\hline FA (U/L) & 312 & 316 & 301 & 314 & 300 & 329 & 293 & 267 & 305 & 217 & 203 \\
\hline GGT (U/L) & 646 & 589 & 425 & 341 & 370 & 383 & 291 & 267 & 228 & 121 & 72 \\
\hline BT (mg/dL) & 10,5 & 12,9 & 15,5 & 19,4 & 21,3 & 19,6 & 13,3 & 12,0 & 8,7 & 5,8 & 3,1 \\
\hline BD (mg/dL) & 8,9 & 10,9 & 13,1 & 16,1 & 17,4 & 15,9 & 11 & 10,8 & 8,1 & 5,3 & 2,7 \\
\hline INR & 1,1 & 1,1 & 1,1 & 1,1 & 1,1 & 1,1 & 1,1 & 1,1 & 1,1 & 1,1 & 1,1 \\
\hline
\end{tabular}

TGO = transaminase glutâmica oxalacética; TGP = transaminase glutâmica pirúvica; FA = fosfatase alcalina; GGT = gama glutamil transferase; $\mathrm{BT}$ = bilirrubina total; $\mathrm{BD}$ = bilirrubina direta; $I N R$ = razão normalizada internacional.

dade clínica a considerar no diagnóstico diferencial de doença hepática.

\section{RESPONSABILIDADES ÉTICAS}

CONFLITOS DE INTERESSE: Os autores declaram a inexistência de conflitos de interesse na realização do presente trabalho.

FONTES DE FINANCIAMENTO: Não existiram fontes externas de financiamento para a realização deste artigo.

CONFIDENCIALIDADE DOS DADOS: Os autores declaram ter seguido os protocolos da sua instituição acerca da publicação dos dados de doentes.

CONSENTIMENTO: Consentimento do doente para publicação obtido.

PROVENIÊNCIA E REVISÃO POR PARES: Não comissionado; revisão externa por pares.

\section{ETHICAL DISCLOSURES}

CONFLICTS OF INTEREST: The authors have no conflicts of interest to declare.

FINANCING SUPPORT: This work has not received any contribution, grant or scholarship.

CONFIDENTIALITY OF DATA: The authors declare that they have followed the protocols of their work center on the publication of data from patients.

PATIENT CONSENT: Consent for publication was obtained.

PROVENANCE AND PEER REVIEW: Not commissioned; externally peer reviewed.

\section{REFERÊNCIAS}

1. European Association for the Study of the Liver. Clinical Practice Guideline Panel: Chair; Panel members; EASL Governing Board representative: EASL Clinical Practice Guidelines: Drug-induced liver injury. J Hepatol. 2019;70:1222-61. doi: 10.1016/j.jhep.2019.02.014.

2. Kim JS, Jang YR, Lee JW, Kim JY, Jung YK, Chung DH, et al. A case of amoxicillin-induced hepatocellular liver injury with bile-duct damage. Korean J Hepatol. 2011;17:229-32. doi: 10.3350/kjhep.2011.17.3.229.

3. Dandakis D, Petrogiannopoulos C, Hartzoulakis G, Flevaris C, Lagoutari D, Drakogiorgos D, et al. Cholestatic hepatitis associated with amoxicillin-clavulanic acid combination. A case report. Ann Gastroentol Hepatol. 2002;15(Suppl 1):85-7.

4. Fontana RJ, Shakil AO, Greenson JK, Boyd I, Lee WM. Acute liver failure due to amoxicillin and amoxicillin/clavulanate. Dig Dis Sci. 2005;50:1785-90. doi: 10.1007/s10620-005-29385.

5. Hautekeete ML, Horsmans Y, Van Waeyenberge C, Demanet $\mathrm{C}$, Henrion J, Verbist L, et al. HLA association of amoxicillin-clavulanate-induced hepatitis. Gastroenterology. 1999:117:1181-6. doi: 10.1016/S0016- 5085(99)70404-X.

6. Herrero-Herrero JI, García-Aparicio J. Corticosteroid therapy in a case of severe cholestasic hepatitis associated with amoxicillin-clavulanate. J Med Toxicol. 2010;6:420-3. doi: 10.1007/ s13181-010-0019-4].

7. Bénichou C. Criteria of drug-induced liver disorders. Report of an international consensus meeting. J Hepatol. 1990;11:2726

8. Maria VA, Victorino RM. Development, and validation of a clinical scale for the diagnosis of drug-induced hepatitis. Hepatology. 1997;26:664-9. doi: 10.1053/ jhep.1997.v26. pm0009303497] 